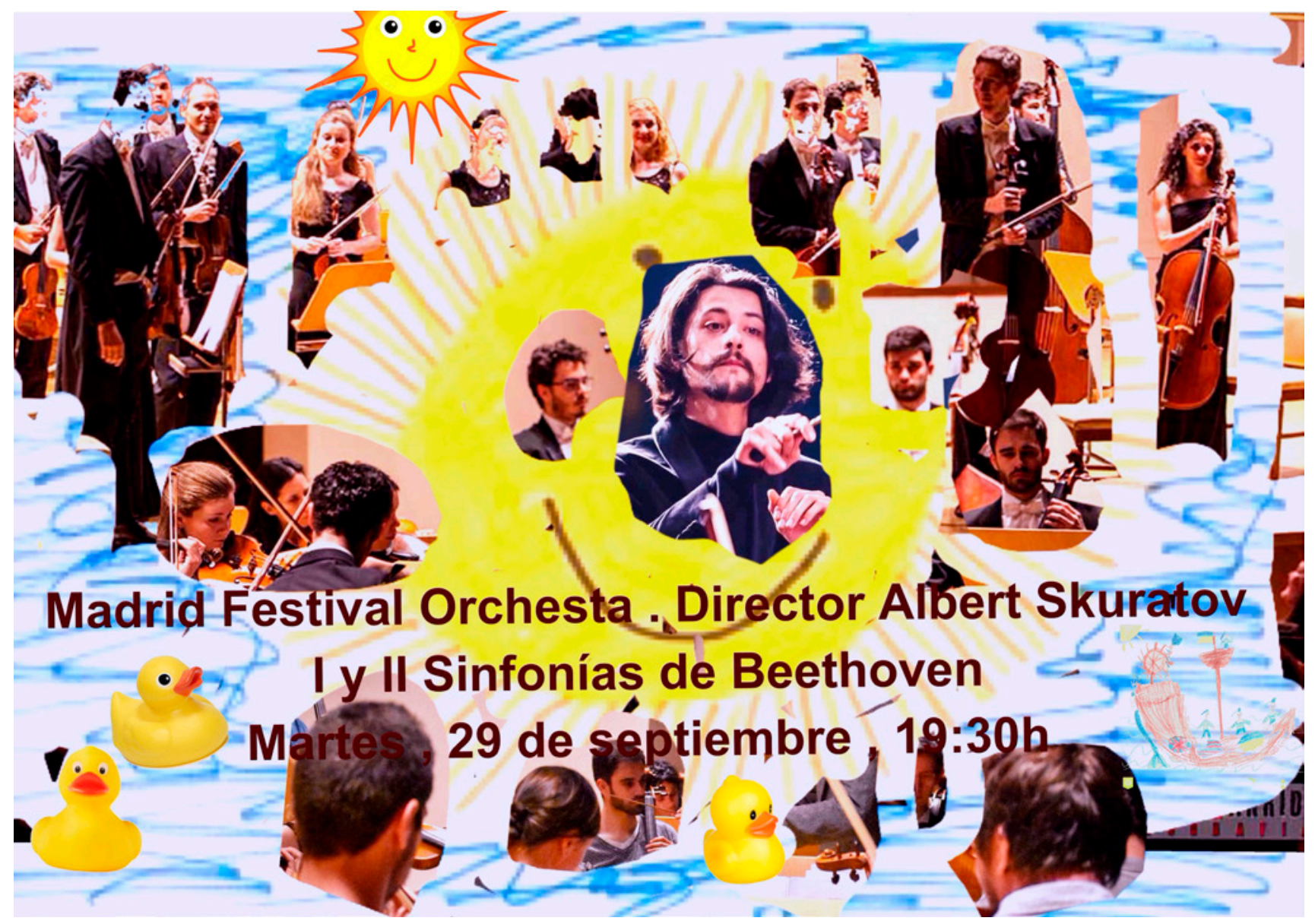

Cartel de «Madrid Festival Orchestra». Director: Albert Skuratov, 2020. Fotografía: El Instante Fundación. 


\title{
EL INSTANTE FUNDACIÓN. \\ UN PROYECTO ARTÍSTICO CONCEPTUAL Y \\ MULTIDISCIPLINAR
}

\author{
EL INSTANTE FUNDACIÓN. \\ A CONCEPTUAL AND MULTIDISCIPLINARY \\ ARTISTIC PROJECT
}

\author{
María Dolores Arroyo Fernández \\ Universidad Complutense de Madrid
}

Resumen El Instante Fundación nació hace cuatro años en el barrio de Palos de Moguer de Madrid con el objetivo de añadir un nuevo espacio de encuentro cultural, expositivo y multidisciplinar. El proyecto está en consonancia con una línea de actuaciones urbano-arquitectónicas y propuestas integrales, que tiene como prioridad dar nuevo sentido a obsoletos edificios y aprovechar así su potencial como espacios expositivos para los nuevos contenidos. Este hecho contribuye a la regeneración urbana y redunda en beneficio de los entes sociales al dotarles de puntos de encuentro que integran diversas disciplinas desde el arte, música, ciencia y conferencias, talleres, estancias. Una programación cultural múltiple, ofrecida en sus contenidos como imagen de lo breve, el presente, de ahí su nombre de marca, y en un espacio diáfano que se distancia de las recargadas salas de exposición más convencionales.

Palabras clave

El Instante Fundación, barrio de Palos de Moguer, espacio expositivo, arte contemporáneo, arte colaborativo, arte de acción, multidisciplinar, el presente.

Abstract El Instante Fundación was created in Palos de Moguer district (Madrid) four years ago with the idea of offering a new space for exhibitions and cultural and multidisciplinary gatherings. This project is in line with a series of urbanarchitectural actions and comprehensive proposals whose priority is to give derelict buildings a new meaning so as to take advantage of their potential as exhibiting spaces for new content. This is a way to regenerate the city which benefits social entities as it provides them with meeting places for such diverse disciplines as art, music and science, which can also host a series of activities such as conferences, workshops, and visits. El Instante Fundación offers a varied cultural program which embodies the idea of briefness and of the present, hence its brand name. Its open space differentiates it from the typical overcrowded showrooms.

Keywords El Instante Fundación, Palos de Moguer Neighbourhood, Exhibition Space, Contemporary Art, Collaborative Art, Action Art, Multidisciplinary, The Present. 


\section{Origen y filosofía del proyecto El Instante Fundación}

El Instante Fundación nació el 23 de enero de 2017 en Madrid a partir del entusiasmo y colaboración de una serie de personas del mundo del arte y arquitectura (Oliva Arauna, Heinrich Ehrhardt, Juan Navarro Baldeweg, Denis Long, Pierre Hubert, José María Sicilia, Luis Enguita, Paloma Lasso de la Vega, etc.), de la música (Santiago Auserón, Marisa Pons, Soledad Cardoso, etc.), y otras figuras de la ciencia, del cine, del teatro, de la intelectualidad y de la cultura en general. Apostaron por la independencia, por no recibir subvenciones $y$ por la libertad en la configuración de sus programas. La presencia de toda una generación que impulsó el arte de los ochenta se unía en este proyecto con las generaciones más jóvenes, las que están apostando por un arte menos protagonista y más colaborativo $\mathrm{e}$ integral en sintonía con las exigencias de estos tiempos. El Instante se concibe pues como un intercambio de ideas y propuestas entre los históricos y los emergentes.

La contribución de socios, unas mínimas aportaciones privadas y públicas y las colaboraciones con otras entidades ${ }^{1}$ con las que se ha establecido acuerdos, son el sostén del proyecto de esta Fundación de la cual su primera directora Esther Suárez, licenciada en Publicidad y RR. PP. en Ciencias de la Información en la UCM, señaló: «Me atrajo la idea de que se trate de un lugar para la reflexión sobre el momento en el que estamos. Sobre el presente desde diversos puntos de vista» (Fuente, 2017). Palabras que reflejan el objetivo principal de El Instante: reflexionar a través del arte,

1 Calcografía Nacional; Escuela Superior de Música Reina Sofía (Fundación Albéniz); Cisneros-Fontanals Art Foundation (Miami); Acción Cultural Española (AC/E); Yamaha España; Fundación PiuMosso; I'm Group / NPO Iwate Future Organization), Tokyo-Ueno, a Global Capital of Culture; Iwate MIrai Kiko; International Library for Children's Literature (Tokio, Japón); Enguita \& Lasso de la Vega Arquitectura; Editorial Anagramar; Fundación Juan March y Festival Proyector. literatura, filosofía, música, ciencia, gastronomía, artes escénicas, sobre nuestro momento presente. Elevándose entonces como substancial propósito la combinación de unas y otras disciplinas.

De esta manera se parte de una tendencia dominante y progresiva de creación de centros de cultura polivalentes, estatales o privados, que busca en ese afán de comunicación y de servicio ciudadano alcanzar al público. Más generalistas o más especializados, estos centros se han ido extendiendo de tal manera que la oferta que presentan es tan variada como rentable y beneficiosa. Son proyectos multidisciplinares en los que intervienen distintos profesionales: desde el artista, diseñador o comisario hasta el gestor y patrocinadores. Proyectos en los que todos son fundamentales para establecer ese diálogo imprescindible con el público. No se trata solo de la obra de arte expuesta físicamente en la sala, también el lugar que ocupa en el espacio expositivo, su significado más profundo o la integración de la obra en un conjunto de actividades, programadas o espontáneas, que la acompañan. Conseguir ese diálogo con el visitante impulsándolo hacia el conocimiento, estimulando su percepción y el disfrute de las obras, es cada vez más labor de un amplio equipo.

El Instante Fundación nace pues en sintonía con este modo de presentar el arte junto a otros productos culturales. Los antiguos debates sobre el valor diferenciado de un tipo determinado de arte, música, literatura, poesía u otras disciplinas «elevadas» parecen haberse zanjado. Sin embargo, El Instante posee su propio distintivo: conceptualmente alude al tiempo, algo tan abstracto como imperceptible, y mantiene ese espíritu renacentista de fusión de la ciencia y materias de pensamiento en un coloquio con el arte. Pero ni el tiempo, ni el espacio son hoy como hace décadas. Los intervalos se acortan, los espacios se expanden, se hacen virtuales, lo físico tiende a desaparecer. «El arte en los últimos decenios 

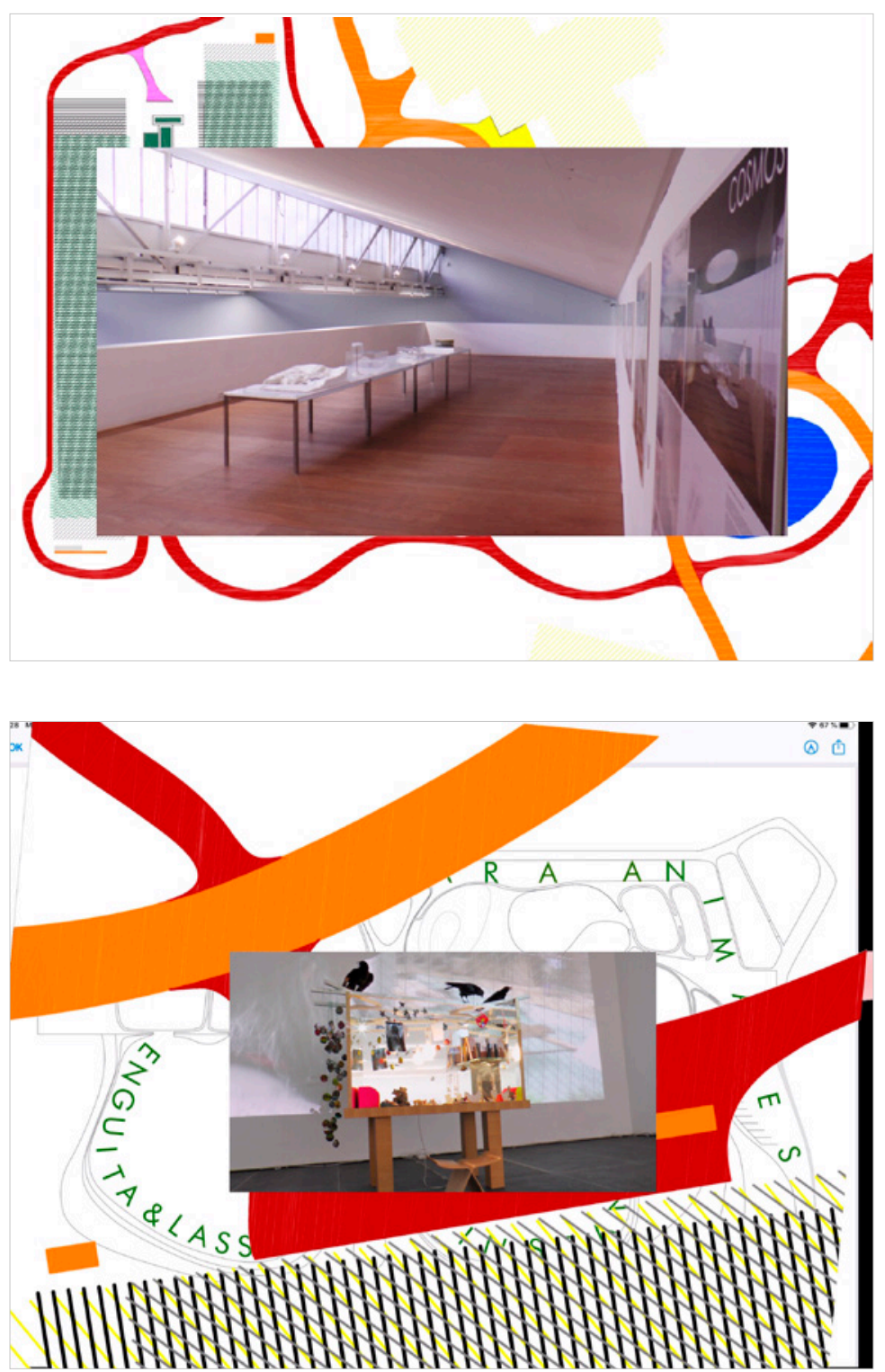

Del proyecto «Casas para animales», Instante Fundación, 2018. Fotografías: El Instante Fundación.

ha desarrollado una paradójica postura frente al tiempo: la inmediatez absoluta del presente continuo subraya lo efímero del momento al mismo tiempo que la infinitud del cambio» (Rivero, 2010: 43). Desde que en el siglo XIX, los fotógrafos y los pintores impresionistas empezaron a atrapar el instante, hoy cada vez se hace difícil retener nuestras vivencias, controlar el tiempo y fijar nuestra mente. En tiempos actuales de premura, las experiencias vividas se nos escapan. Atrapar ese instante es el objetivo de los proyectos pensados para esta
Fundación, cuyo equipo actual ${ }^{2}$ está dirigido desde enero del 2018 por Cristina Pons.

Se explica así para esta fundación el nombre de El Instante: miradas a un presente que jamás volverá. Se revela entonces toda una filosofía

2 Forman parte del equipo de El Instante: Cristina Pons (directora), licenciada en Filosofía y Letras por la Universidad Autónoma de Madrid, especialista en museografía y en la concepción de exposiciones; Ágata Sánchez Duarte (desarrollo de proyectos y comunicación), a la que se agradece la ayuda prestada e información aportada para la elaboración de este artículo; y Ramón Sánchez López (audiovisuales y sala). 
sobre la supuesta inutilidad de los objetos materiales y, en contrapartida, un significado más profundo a descubrir en ellos. En definitiva, las propuestas se conforman según una estudiada desorientación hacia lo que el público se va a encontrar al cruzar el gran portalón que sirve de entrada al edificio de El Instante. Un concepto en parangón con iniciativas que ponen el foco en lo aparentemente no trascendente, desde la ya inmortal Fuente (1917) de Marcel Duchamp al Manifiesto del profesor de literatura, Nuccio Ordine La utilidad de lo inútil (Ordine, 2013). El libro de este autor italiano es una recopilación de opiniones de filósofos y de pensadores sobre la avidez del conocimiento, en palabras de Fernando Savater «... sobre la importancia de seguir tutelando en escuelas y universidades ese afán de saber y de indagar sin objetivo inmediato práctico... ${ }^{3} »$. En un espacio de arte y cultura, como el de El Instante, la gran dimensión del lugar, el vacío o la pequeñez de objetos artísticos inútiles allí expuestos cobran vida y es material dispuesto para la reflexión. En definitiva, el objetivo de El Instante Fundación es aportar algún punto de luz a estos tiempos de crisis e incertidumbre.

\section{El edificio en su contexto urbano}

El centro de El Instante se ubica en la calle Palos de la Frontera, 204, barrio de Palos de Moguer, perteneciente al distrito de Arganzuela en el Ensanche Sur de Madrid. Con su forma de doble triángulo abarca un área bordeada al noroeste por las Rondas de Valencia y de Atocha, al este por la calle de Méndez Álvaro, al sur por las calles del Ferrocarril y Bustamante y al suroeste por la de Embajadores. Junto con el de Tetuán al norte de la ciudad, ambos situados en el borde de la almendra central, el distrito del sur sufre

\footnotetext{
3 Fernando Savater, cita en la portada del libro Nuccio Ordine: La utilidad de lo inútil. Manifiesto. Barcelona: Acantilado, 2013. 4 Antes llamada calle Palos de Moguer, en 1986 se cambió de nombre por el actual.
}

importantes transformaciones entre los años 1979 y 1999 en lo que se concibe como una «normalización urbanística de la periferia». Arganzuela se transforma totalmente

... desde la reordenación de la glorieta de Atocha hasta los nuevos espacios verdes y residenciales ligados a la operación del Pasillo Verde Ferroviario y a la creciente conversión de espacios industriales obsoletos en nuevos barrios residenciales en Legazpi en torno a Méndez Álvaro (López de Lucio, 2003: 123).

La Estación de Atocha remodelada por Rafael Moneo en 1984 enclavada en «... el conflictivo eje sur de la ciudad, uno de los más castigados por el alocado desarrollismo de los años sesenta y, por tanto, pieza clave para una redefinición de la degradada imagen de la capital» (Calvo Serraller, 1984: 28).

Las varias etapas en la evolución del barrio actual de Palos de Moguer, cuya delimitación como tal data de 1971, han sido analizadas por Rubio (1982): desde el Plan Castro de 1860, siguiendo la etapa de consolidación desde finales del siglo XIX a 1935 hasta una fase de renovación y cambios, que se acelera a partir de 1970 cuando el barrio va incorporándose al centro de la capital. Por este lugar y por todo el Ensanche Sur pasan los accesos a la ciudad de las carreteras de Andalucía y Toledo.

Este trasiego ha fomentado la ubicación en sus aledaños de múltiples empresas de transporte de viajeros y mercancías, que se singularizan en el sector central en la Estación Sur de Autobuses (1971), que ocupa toda una manzana, la empresa de viajeros AISA, y otras múltiples casas de transporte de mercancías (Rubio, 1982: 235).

Situada en el entorno del paseo de las Delicias y la calle Canarias en el mismo distrito de Arganzuela, la Estación Sur de Autobuses ${ }^{5}$, una vez clausurada a finales de los noventa del pasado siglo pasa a convertirse en Centro

5 Edificio construido por Mariano García Benito entre 1968 y 1969. 


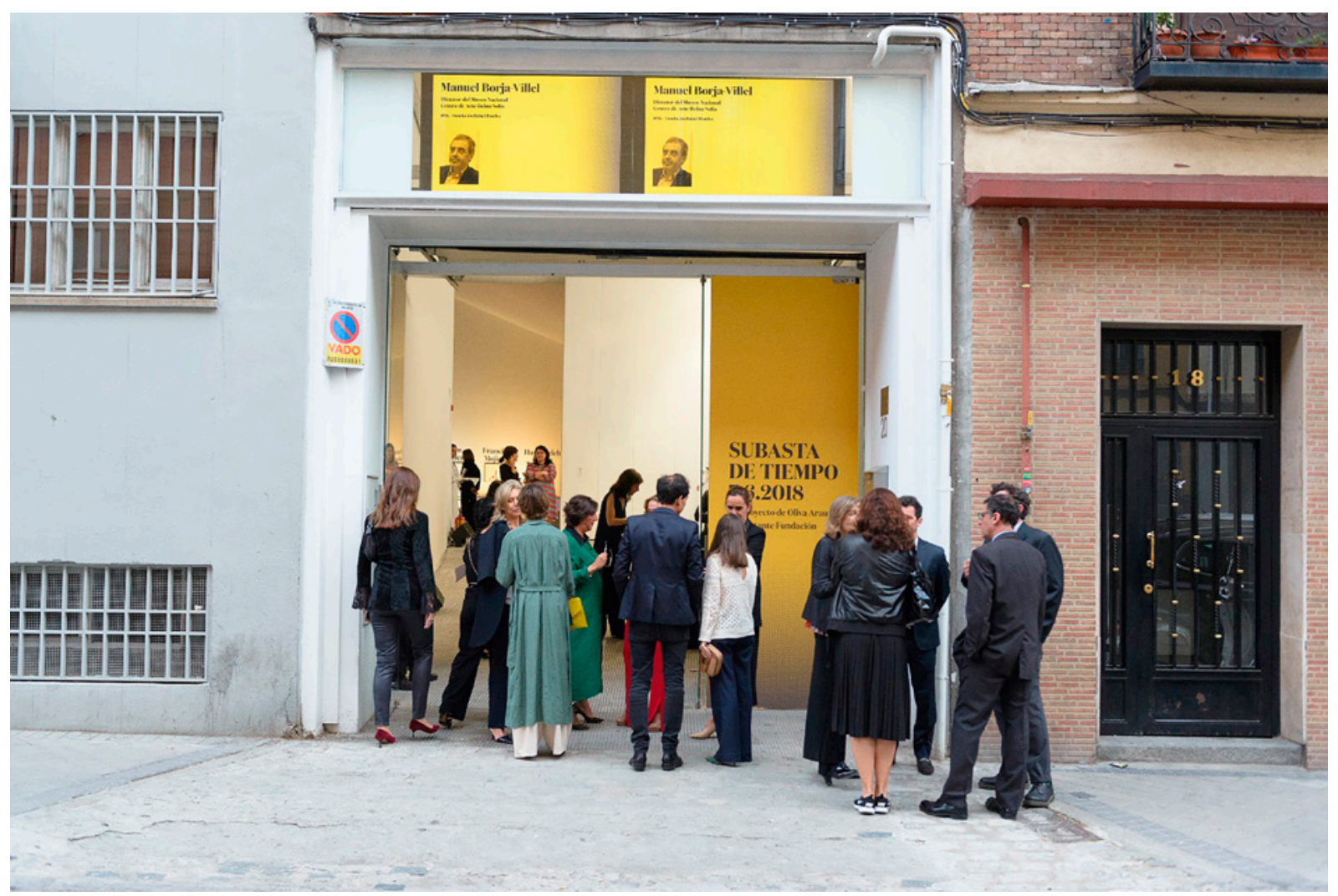

Puerta de entrada a El Instante Fundación. Exposición: «Subasta del Tiempo», 2018. Fotografía: El Instante Fundación.

Público. Para los vecinos esta transformación supuso una ventaja en todos los sentidos de pasar de los ruidos y humos que soportaban a diario a «... aparcar sus coches en las antiguas dársenas, bañarse $o$ hacer deporte en el polideportivo, utilizar la plaza pública, acudir a cursos y exposiciones o visitar el centro de día para la tercera edad» (Medialdea, 2001). Las primeras polémicas sobre qué hacer con el edificio de la estación dieron paso al primer centro integrado municipal, inaugurado por el alcalde, José María Álvarez del Manzano, y por su principal impulsora, la primera teniente Mercedes de la Merced. Según los autores del proyecto (Equipo INCA) ${ }^{6}$ pretendían fomentar

6 Proyecto arquitectónico realizado por cuatro jóvenes arquitectos, el equipo INCA, que ganaron el concurso. Entre el jurado había miembros de asociaciones vecinales del distrito. «Un Joven equipo pluridisciplinar sorprende en el concurso de la antigua estación sur de autobuses de Madrid». Pasajes de Arquitectura y Crítica, núm. 1, noviembre 1998.
... el carácter colectivo de las actividades que alberga, el edificio y su entorno pretenden convertirse en un lugar de paso y encuentro de los vecinos y usuarios (...). La fluidez visual y espacial se prolonga en las circulaciones interiores, desplazando las actividades al perímetro en un continuo reclamo de la luz y del visitante. (COAM, 2014).

A este Centro Cívico municipal se sumó tiempo después otro sitio privado, El Instante Fundación, que eligió precisamente para su sede el edificio de las antiguas cocheras de la Estación Sur de Autobuses, que estaba situado en la cercana calle de Palos de la Frontera. Al tiempo que se cerró la estación, las cocheras habían dejado de ejercer su función como tal. Durante años entraban y salían los vehículos por la rampa que hoy sirve de acceso a una gran nave central rehabilitada como espacio para eventos. Sin embargo, aunque se sobreponga 


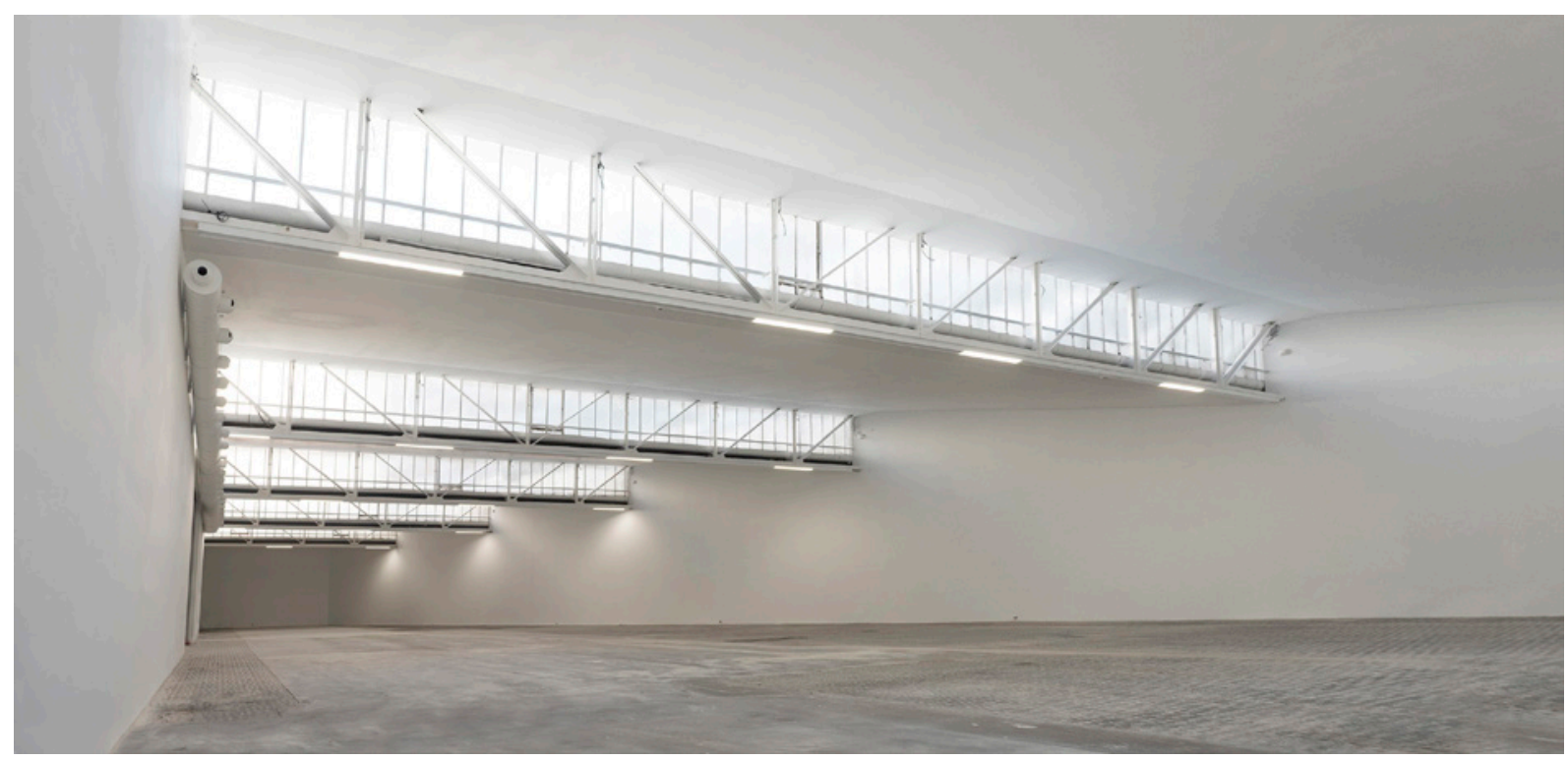

Espacio interior: Nave para exposiciones y eventos. Fotografía: El Instante Fundación.

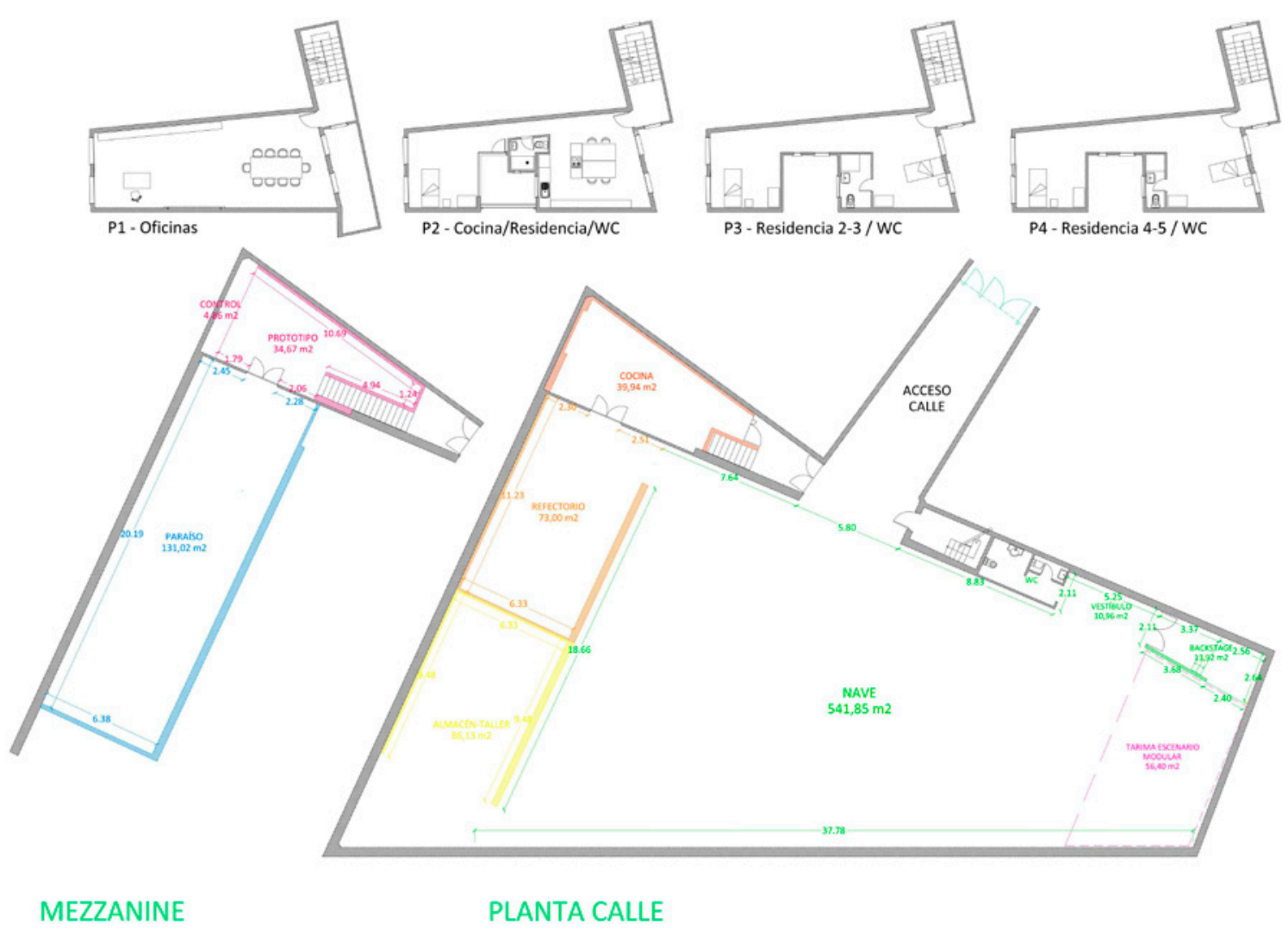

Plano de los distintos espacios. Fotografía: El Instante Fundación. 
esta otra función de lugar de cultura, permanece el espíritu de la antigua construcción.

Con esta otra propuesta de enfoque transversal se contribuye a la revitalización del barrio. El tejido cultural va tomando forma y se va expandiendo desde Lavapiés y Embajadores -zonas ya dotadas de galerías de arte, Casa Encendida, Tabacalera, Museo Nacional Centro de Arte Reina Sofía o el Circo Price- hacia el sur. La mayoría no son edificios de nueva planta sino antiguas construcciones fabriles e industriales rehabilitadas, como Matadero, Estación de Delicias, Medialab, CaixaForum, etc. Unas áreas de Madrid muy dinámicas cuyas ventajas se han ido proyectando también hacia el sur, ampliándose su oferta a zonas tradicionalmente menos dotadas culturalmente.

En el uso de un garaje como sala de exposiciones fue pionero Fernando Vijande, que dinamizó el mundo del arte durante la Transición cuando en los años ochenta abrió galería en la calle Claudio Coello, distrito de Salamanca. Años después, en mayo de 2013 La Fábrica ${ }^{7}$ ocupó para su nueva sede un garaje en la calle Alameda, en el barrio de las Letras, que se convirtió en importante punto de encuentro dedicado a la cultura. El aspecto exterior de este tipo de inmuebles rescatados ofrece cierta curiosidad y del mismo modo recelo. El Instante Fundación a simple vista tampoco posee especial interés en su fachada que invite a penetrar en él. Los grandes carteles del evento anunciado sirven de reclamo mientras la gran rampa de acceso, por donde antes pasaban los autobuses para acomodarse en las cocheras, ahora se convierte en el espacio de recepción que dirige a los visitantes a una amplia y sorprendente nave central. Un público, local y de fuera del barrio, cada vez más amplio y heterogéneo, es atraído hacia este lugar que le prepara más que

7 Fundada en 1995, La Fábrica, galería de arte y editorial de libros de fotografía, es la impulsora de proyectos como PHotoESPAÑA, la revista Matador, el festival de cine en Internet Jameson Notodofilmfest o el festival de literatura Eñe. para mirar para reflexionar. La cuestión que atañe a las construcciones para el arte (museos, centros de arte contemporáneo) y la polémica sobre su funcionalidad como contenedores de arte y la ostentación de la condición artística del edificio mismo, ha sido ampliamente estudiada por Layuno (2004).

\section{Espacio expositivo y programación}

En un edificio de estas características, el tipo de eventos o de exhibiciones no pueden ser los usuales. La web de gestión cultural «Manual Atalaya» analiza las diferentes tipologías de equipamientos desde los especializados (artes escénicas, musicales, artes plásticas o la incorporación de equipos de nueva generación) a la introducción de equipamientos polivalentes y de proximidad (Álamo, s.f.), como el que podría detentar El Instante Fundación. Pero aquí el foco está puesto en crear espacios para fomentar la indagación, lo que se produce o se exhibe no está en función de un mero y superficial recreo visual. Interesa el tiempo como concepto, apresar el instante, materializar aquellas vivencias que perdemos si no las atrapamos. Esta idea es pues la particularidad ylo que mueve a esta institución, que fue concebida para dedicar un $40 \%$ de su programación a la improvisación. Consecuentemente, el espacio expositivo y los proyectos que se desenvuelven en él van coordinados modelándose en una unidad.

Si su filosofía consiste en alejarse de golpes de efecto, no llamar la atención, lo que ya se evidencia en el edificio que sirve de contenedor y en la entrada de lo que fue el antiguo garaje de la Estación Sur de Autobuses. Al ser un espacio polivalente para cualquier tipo de evento, su interior debe estar adaptado a ese tipo de funcionalidad múltiple. Las características constructivas y amplitud de un aparcamiento de autobuses como este constituyen pues el lugar idóneo para poner en marcha el proyecto de El Instante. 

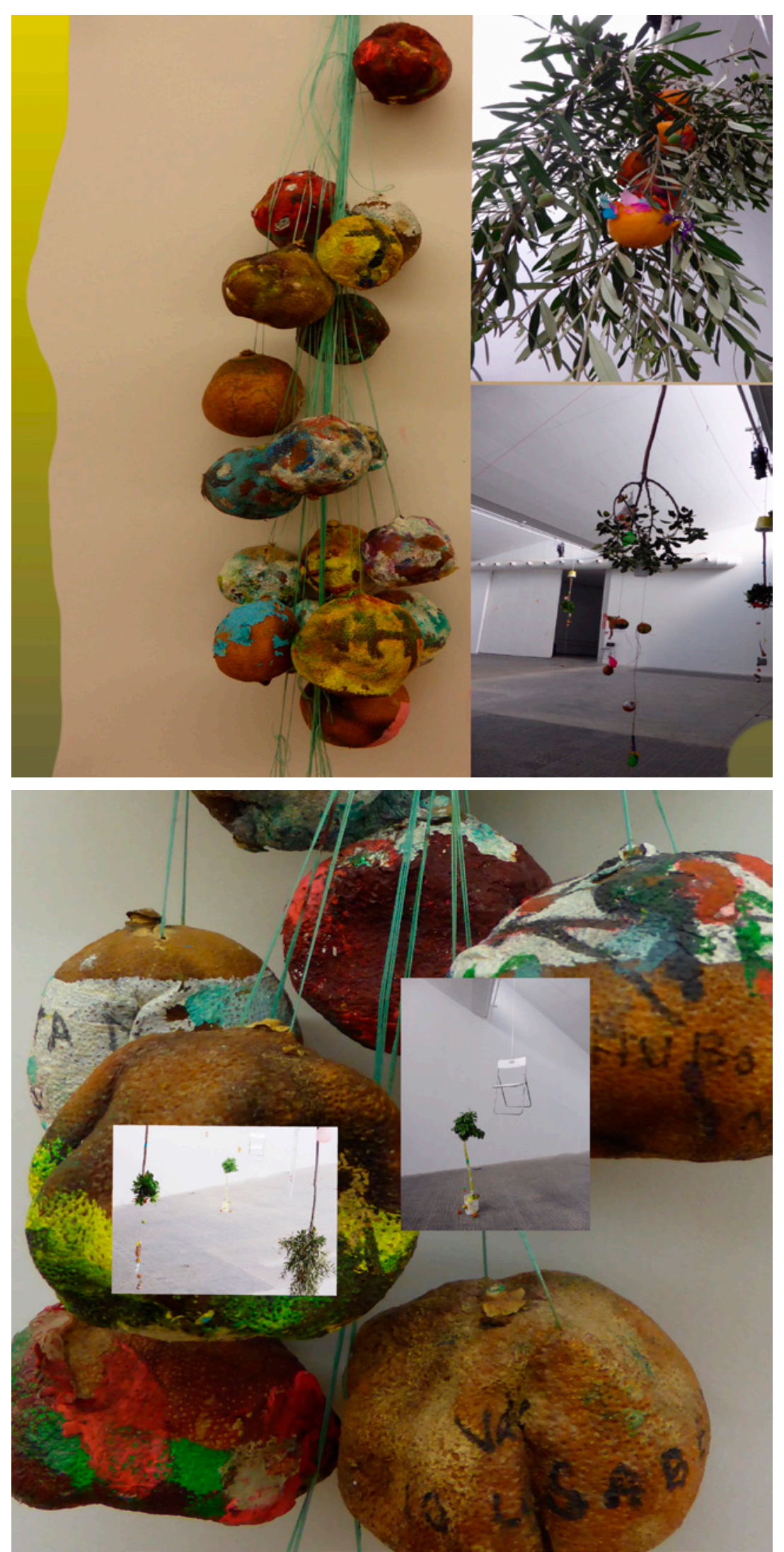

De la exposición «Mudar la piel», Instante Fundación, 2019. Fotografía: El Instante Fundación. 


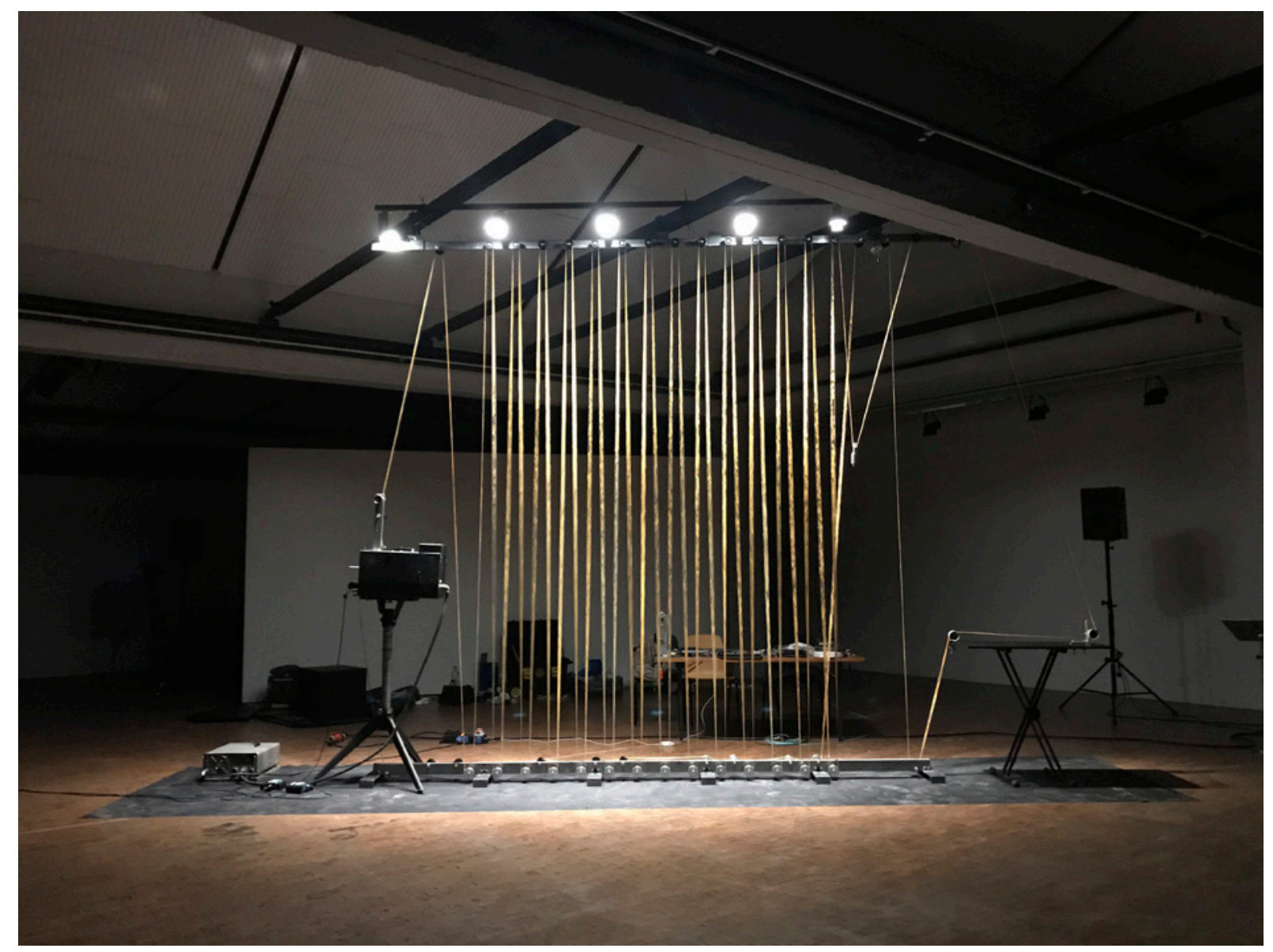

Pantalla-instalación. Gold Film. Deneb Martos y Wade Matthews. Fotografía: El Instante Fundación.

Su superficie total es de unos $890 \mathrm{~m}^{2}$ que incluye la rampa de entrada, la gran nave con un escenario modular, que se utiliza para las exposiciones, proyecciones, conciertos y demás acciones artísticas; aparte de otras dependencias como aseos, sala balcón, sala refectorio, cocina industrial, almacén; camerinos en las plantas tercera y cuarta para los artistas que se alojen allí en Residencia o para invitados con algún proyecto en marcha. "Las estancias varían según el objetivo del residente: viajes de toma de contacto o acciones puntuales o de mayor duración para el desarrollo de talleres o trabajos de investigación». En la selección de los proyectos se da prioridad a aquellos que tengan un carácter más experimental, para la reflexión y pensamiento sobre el presente. De ahí que entren «escritores, cineastas, poetas, músicos, filósofos e historiadores, investigadores en cualquier disciplina científica, social o en humanidades, e incluso artistas que puedan usar el espacio para pequeños y medianos formatos ${ }^{8} \%$. Cuenta también con un sistema audiovisual, proyección, sonido, microfonía, iluminación, fibra óptica. Asimismo, cuando esos espacios están disponibles, pueden ser alquilados para eventos privados. Todo ello es importante destacarlo puesto que las infraestructuras y el equipamiento técnico ofrecen la medida del tipo de actividades y exhibiciones

8 Más información de cada una de las dependencias, la distribución de espacios y dimensiones de la Residencia, las citas, así como otra información, puede consultarse en la web de El Instante Fundación: https://www.elinstantefundacion.org/ 
que se pretende en este particular espacio para el arte.

La programación ${ }^{9}$ de El Instante Fundación se organiza en consonancia con el espacio expositivo y escenográfico existente $y$, al contrario, reclama este un tipo de actividades que requieren un despegue por toda el área de la gran nave, introduciéndose en las zonas aledañas, cocina, sala refectorio o sala balcón. Todos los espacios son factibles de ser recorridos, pues en ellos pueden descubrirse desde piezas expuestas dialogando con el espacio hasta algún actor protagonista del evento recitando un poema o tocando una trompeta. De cualquier manera, siempre para sorprender y procurar un margen para pensar sobre el hecho artístico. En definitiva, como se dijo más arriba, espacio y programación constituyen una unidad hasta el punto que no es concebible el uno sin la otra. Un plan muy característico de eventos puntuales, ejes temáticos, presentaciones de libros, conferencias, talleres, conciertos de música, exhibición de obras de arte, etc. Disciplinas que se interrelacionan, que interactúan entre sí en lo que sería una nueva y original propuesta que se suma a la vida cultural de Madrid.

Se señalan aquí algunos ejemplos de una interesante y más basta programación, que se detalla en los distintos apartados de la página web de la Fundación. En esta labor de equipo tiene una especial transcendencia el ciclo de conciertos de Música en El Instante, en colaboración con la Escuela Superior de Música Reina Sofía, que incluye desde música de cámara hasta aquella más experimental. Pero no se trata de conciertos sin más, sino que cada actuación confluye con otras prácticas artísticas. Un encargo de El Instante que se orientó según este plan integrador fue el estreno del concierto de Juan Manuel

\footnotetext{
9 Más información sobre las actividades, eventos, obras comentadas o citadas en el texto sobre la programación pueden consultarse en la web de El Instante Fundación: https://www. elinstantefundacion.org/
}

Artero Cuna y paseo de los erizos, que se acompañó con la instalación sobre un paseo por minibares móviles titulada Frente al bar, una creación del artista plástico José María Sicilia (6 junio 2019). El concierto diseñado por Artero disponía de todos los espacios de la sala reformada, como un recorrido por distintos ámbitos sonoros.

Una demostración de fusión entre música e imagen fue el concierto de improvisación libre Gold Film [35 mm, loop infinito], de FILMADRID en colaboración con El Instante, celebrado el 11 de junio de 2019. Una performance en la que se investigaba con la materia y los sonidos, un diálogo entre la artista visual Deneb Martos y el músico experimental Wade Matthews ${ }^{10}$. «La puesta en escena remite a una suerte de cine expandido, cuando la instalación escultórica de películas doradas dispuestas verticalmente se activa con un movimiento ascendente y descendente para transformarse en una pantalla de proyección en blanco y negro» (Angosto, 2019).

El planteamiento del sonido para la proyección de Gold Film partió de lo que para Wade Matthews es una cuestión central de la improvisación: el diálogo. En este caso, el diálogo con lo proyectado y con el mismo proceso de proyección. Y, como todo diálogo nace de la escucha, como determinante de contenido y garante de coherencia, sus propias palabras ${ }^{11}$ explican su proceso de creación:

Comencé el proceso poiético escuchando los sonidos generados por el viejo proyector alemán (1960), incluidos sus motores, el paso de la película por los engranajes y los ruidos emitidos por el lector óptico de banda sonora mientras pasaba el oro en paño fijado a la película. Con esos pocos sonidos, la mayoría grabados y la del lector óptico en tiempo real mientras se proyectaba la película, elaboré un acompañamiento orgánica-

10 Gold Film, Deneb Martos \& Wade Matthews. Vanguardias Live, Filmadrid Festival 2019. Puede verse en el siguiente enlace: https://vimeo.com/371582541

11 Las palabras citadas fueron recogidas en entrevista al músico Wade Matthews. 


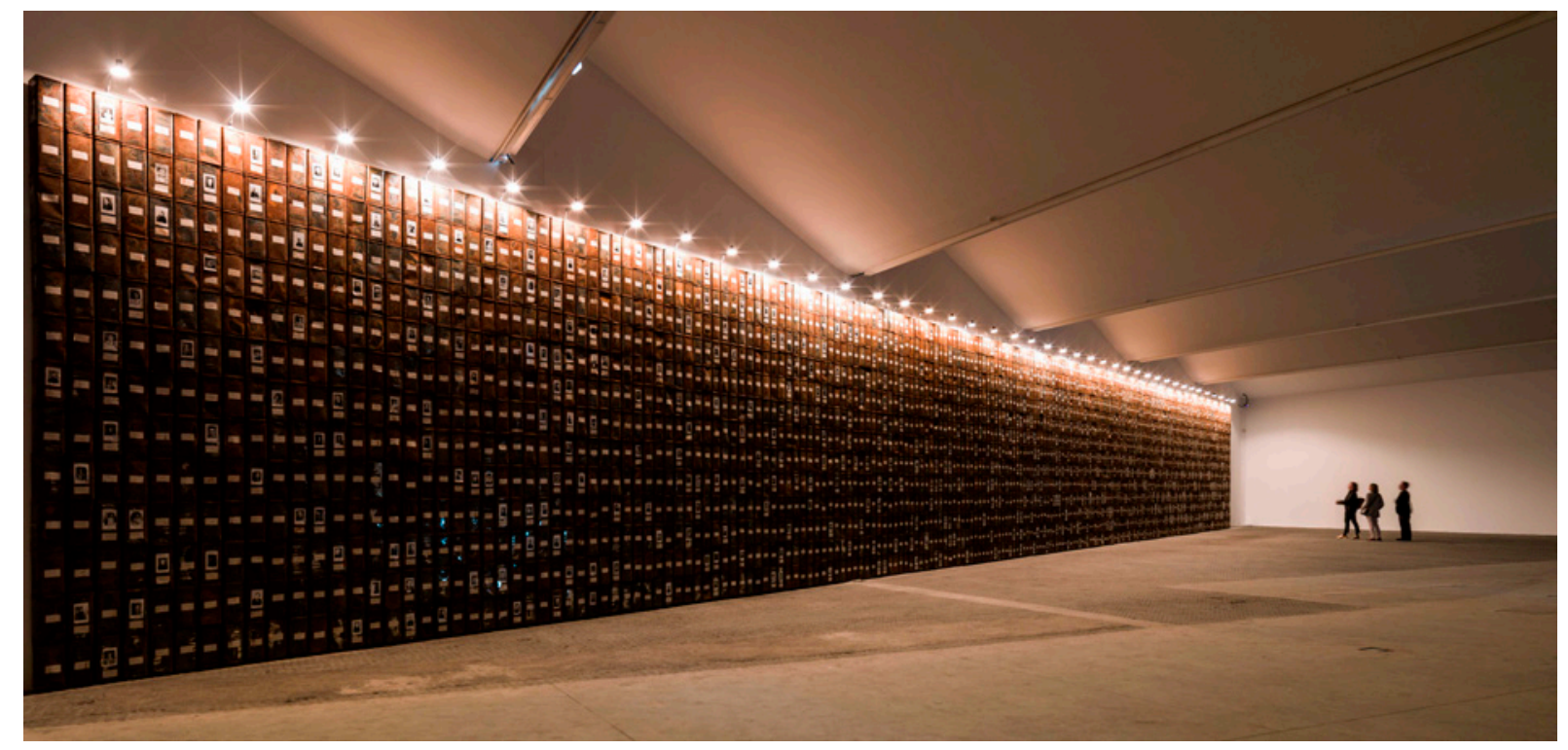

Christian Boltanski, Les registres du Grand-Hornu (1997). Fotografía: Jaime Elechiguerra. El Instante Fundación.

mente ligado tanto al contenido visual como al mismo proceso de proyección.

El resultado tenía la misma intermitencia, los mismos cambios de densidad, contrastes y ritmos que lo visible. Igualmente los cambios de "color», velocidad y el cinetismo (nunca mejor dicho) de la proyección en vídeo que ocupaba la pantalla enfrente de la de la proyección en película de $35 \mathrm{~mm}$.

El tamaño y resonancia de la sala, la colocación de las dos pantallas, una analógica y la otra digital, y la posibilidad para el público de desplazarse a voluntad por todo el espacio con el sonido proyectado desde arriba, contribuyeron de forma importante a la experiencia total. Y ahondando en la importancia de la escucha para el improvisador, Wade Matthews ha escrito (2012: 150):

Cuando el improvisador escucha el momento, no lo vive como algo fijo, sino como el flujo del cambio. Cuando lanza su sonido al momento, no lo vive como algo fijo sino como el cambio del flujo. Vivir el flujo es escuchar. Vivir el cambio es escuchar.

Para el improvisador, la escucha es el miembro prensil de la aceptación. Escuchar es tambalearse en el borde entre el pasado -lo ya acontecido y tan irreversible como necesariamente aceptadoy el presente. Ese presente momento, presente y del presente, esa caída hacia el futuro, es el deliberado desequilibrio del barroco, el fluir asido por la escucha, sondeado por el sonido. Si el flujo es la cuerda floja y el improvisador el funámbulo, la escucha es entonces su pértiga, su constante reequilibrio; y su sonido, los pasos que da. Finas sus zapatillas, para sentir mejor la cuerda.

El Instante se inauguró el 23 de enero de 2017 con una instalación compuesta por un muro de cajas de hojalata oxidada de más de 40 metros de largo. En ellas figuraban los nombres de unos 3.000 mineros que trabajaron en la antigua explotación de carbón del GrandHornu, en Bélgica. La obra titulada Les registres du Grand-Hornu ${ }^{12}$ de Christian Boltanski fue creada en 1997 en recuerdo de cada uno de los mineros y no del colectivo. Como se nos dice desde la propia Fundación: «De esa manera, en el instante de su contemplación, la obra de Boltanski los devuelve al presente, suscitando cuestiones sobre sus vidas y también sobre nuestra propia existencia».

12 Pieza propiedad del Musée des Arts Contemporains de la Fédération Wallonie-Bruxelles au Grand-Hornu. 


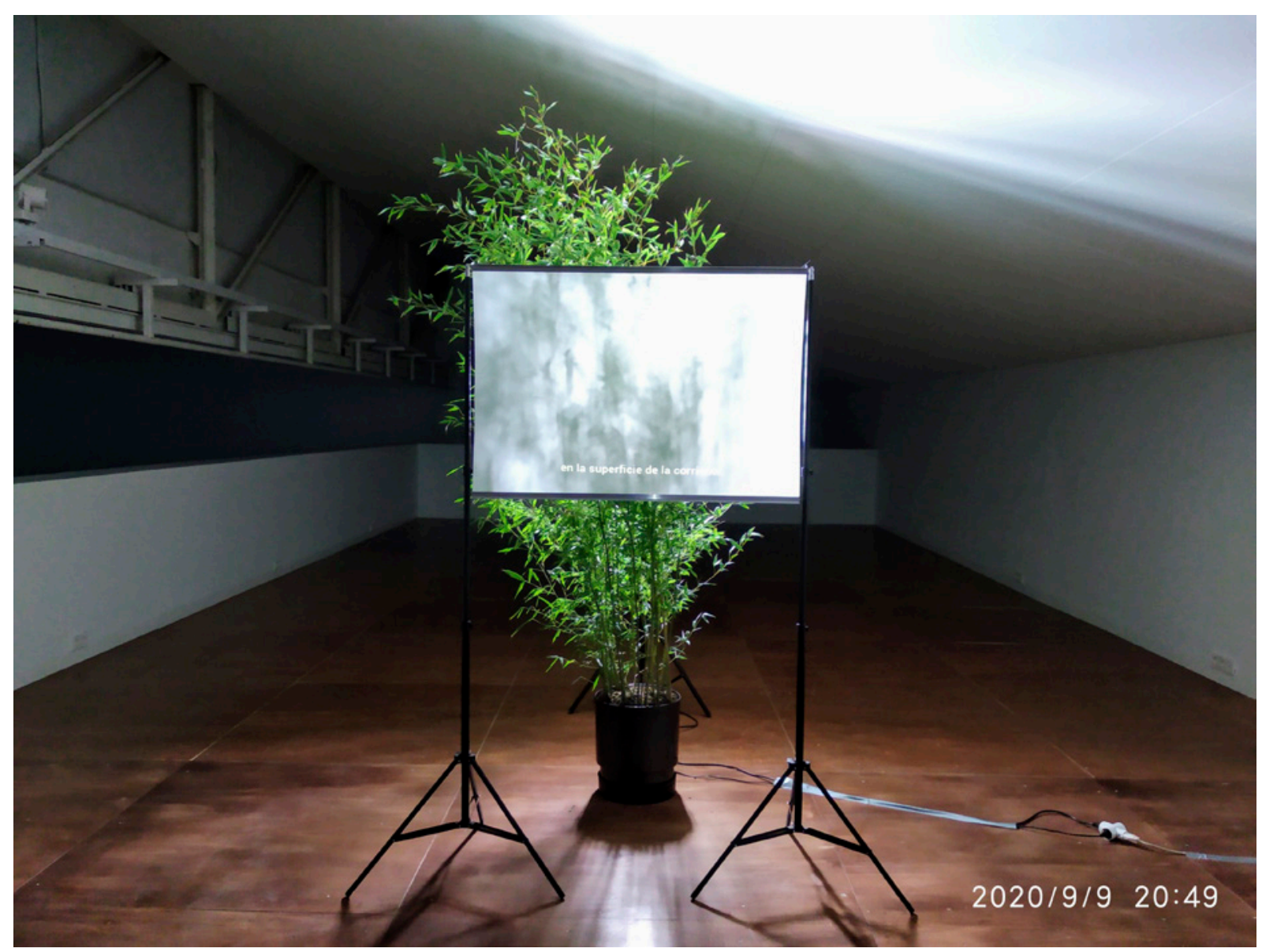

Abelardo Gil-Fournier, La vibración de los juncos (2019). Proyector Festival de Videoarte 2020. Fotografía de la autora.

Otra gran muestra monográfica de peso fue la doble exposición que rindió homenaje a Ulrich Rückriem en su ochenta aniversario. A esta iniciativa que corrió a cargo de la Galería Heinrich Ehrhardt, a través de la cual el artista ha sostenido un importante vínculo con España, se sumó El Instante Fundación. Entre mayo y junio de 2019, mientras la galería exponía The Last Fifty Years, una instalación de ocho esculturas independientes realizadas entre 1968 y 2019, siendo esta la primera vez que se exponían todas juntas, la sede del Instante acogió en sus salas Kosmos (2009-2019). Estas obras y estudios sobre papel son de enorme relevancia para entender su concepción del dibujo según una fórmula matemática a manera de diagramas, el color y el volumen escultórico. Arte, ciencia, tiempo, espacio. Como queda expresamente manifiesto, la geometría y el fraccionamiento son partes fundamentales de la obra del autor, y Kosmos lo demuestra a la perfección: «Indagar en la geometría y el fraccionamiento es parte imprescindible de su obra y Kosmos refleja este aspecto con precisión».

Junto a Boltansky o Rückriem, otra figura prestigiosa del arte contemporáneo internacional fue acogida en El Instante: Nam June Paik. La muestra titulada "Del Siglo XviII a Matrix», reunía obras del coleccionista Pierre Huber, el cual tuvo un encuentro con los asistentes el mismo día de la inauguración, febrero 2018. Fundador de Art \& Public Gallery (Ginebra), Huber considera el vídeo un instrumento privilegiado de expresión del arte contemporáneo que posee su lenguaje específico. Con el inicio de esta muestra dedicada a un pionero del vi- 
deoarte, lo audiovisual va a jugar un papel determinante en la programación de El Instante, no solo como medio de acompañamiento integrado a otras obras expuestas sino como obras de arte en sí mismas.

El Instante ha hospedado varias veces ${ }^{13}$ el Festival de Videoarte Proyector. Bajo el título Naturalezas desplazadas, la $13^{a}$ edición del Festival, celebrada entre los días 9 y 12 de septiembre de 2020, marcó el comienzo de la temporada 2020-2021 de la Fundación, desde la cual se nos anuncia: «En estas piezas de videoarte, una serie de desplazamientos mínimos, que son a la vez físicos y de sentido -pequeños gestos, en ocasiones incluso rudimentarios- tienen la capacidad de provocar una percepción extrema y de revelar una realidad más porosa de lo que habíamos advertido. Un festival que ocupa varias sedes de Madrid».

Una de las obras expuestas fue la de Abelardo Gil-Fournier La vibración de los juncos (2019), una instalación que combina prácticas científicas de primeros del siglo $\mathrm{xx}$ con los dispositivos pioneros de la imagen en movimiento. Se pregunta en ella si la imagen reproduce el proceso vital de las cosas o es el tiempo de la imagen el que se proyecta al mundo fuera de ella. Una idea muy metafísica que encaja en las propuestas que interesan a El Instante y que obligan a repensar la obra más allá del objeto audiovisual en sí.

El teatro, junto a lo audiovisual, la acción, grabación y proyección, fue una apuesta de El Instante para conmemorar el Día Mundial del Teatro y en el marco de la celebración del Bicentenario del Museo del Prado. El 28 de marzo de 2019, mediante las herramientas de expresión actual se llevó al Museo del Prado a los protagonistas de una obra de Cervantes: Persiles y Sigis-

13 El Instante ya había albergado en septiembre de 2018 y 2019, la $11^{\text {a }}$ y la $12^{\text {a }}$ ediciones de dicho Festival de videoarte Proyector. Una, «Voces, polvo, escudos y mentiras», mostró piezas de vídeos de 5 artistas, mientras que la siguiente giró en torno al miedo, una indagación en lo imprevisible, la repetición o el desorden. mund $a^{14}$. Resultó una sorpresa para los visitantes que asistieron a un encuentro inesperado entre los «actores» ${ }^{15} \mathrm{y}$ las colecciones del museo. El recorrido, que comenzó junto a Carlos v y el Furor de los Leoni, continuó por la Galería Central con Tiziano y Guido Reni, para dirigirse a las salas de Velázquez. Esta es una práctica cada vez más generalizada: mantener un diálogo con las obras permanentes del museo utilizando vídeo, acción, performance o a través de la inclusión de obras de artistas contemporáneos encaradas a los fondos museísticos expuestos. En los programas de los museos: Thyssen, Lázaro Galdiano, Academia de Bellas Artes de San Fernando, o el mismo Museo del Prado, entre otros, encontramos varios ejemplos. Convertir el museo en un escenario donde ocurren cosas ajenas a él permite al público unas lecturas renovadas y nuevas perspectivas sobre las colecciones; lo que requiere aguzar otros sentidos que solo la vista, y trabar conocimiento con otras materias ${ }^{16}$.

Significativa apuesta fue la mirada personal a través de la fotografía de Javier Campano sobre las ficciones (patrañas) de su hermano el artista Miguel Ángel Campano ${ }^{17}$. La exhibición «Las patrañas de Miguel Ángel Campano»se compone de 49 fotografías realizadas entre el 2018, fecha del fallecimiento de Miguel Ángel, y el 2019, a partir de objetos realizados por el artista entre 2004 y 2017.

Estas piezas-instalaciones de Miguel Ángel Campano son azucarillos, restos de medicina, tabaco y otros objetos, patrañas. El artista se ha recreado en cosas procedentes de sus íntimos recuerdos, ha fijado la vista en algo que cuando se deshace se queda en nada, el tiempo lo destruye.

14 Trabajo realizado en colaboración con AC/E, José María Sicilia y El Instante Fundación.

15 La relación de participantes de distintas disciplinas puede consultarse en: https://www.elinstantefundacion.org/proyectopersilesysigismunda

16 A Persiles y Sigismunda le siguió la película presentada por el Instituto Cervantes de Budapest Sobre vivir en El Prado dirigida y producida por El Instante, del 18 al 24 de mayo de 2020, con motivo del Día Internacional de los Museos.

17 La Fundación posee en depósito junto al legado artístico de Esther Ferrer el de la obra de Miguel Ángel Campano. 
En los proyectos propios, El Instante se convierte él mismo en artista al concebir ideas que materializa en obras, acciones e instalaciones que giran en torno a distintos ejes temáticos, por ejemplo, Subasta de Tiempo (2017). El tiempo como la divisa de nuestra época. Una serie de personas que son referentes del arte y de la cultura, tal como se anuncia desde la misma Fundación:

Anticiparon el tiempo, lo proyectaron y han hecho del futuro una espera y una esperanza. Estas personas excepcionales han donado $25 \mathrm{minu}$ tos de su tiempo que se subastarán durante una cena de gala el jueves 7 de junio de 2018 en nuestra sede en Madrid. Del dinero recaudado en la subasta, el 50\% de cada remate irá destinado a la ONG escogida por el donante y la otra mitad, a las líneas de acción de El Instante Fundación.

La consecuencia de la muestra anterior fue ¡Resiste! Una obra que habla de la creación en el tiempo, una combinación entre teatro y objeto artístico que se presentó entre junio y julio de 2018. Se trataba del rastro de aquella otra acción que reunió a más de 250 actores en la sede de El Instante Fundación alrededor de la idea de entregar el tiempo. El objetivo de este acto artístico fue compartir con el público la huella de aquella acción, impulsarle a pensar e incitarle a una reacción estética. «Los fragmentos de lo sucedido darán lugar a una historia, la que cada uno quiera reconstruir. Objetos, documentos, imágenes y sonidos conforman la memoria selectiva de una acción, el rastro de un proceso creativo en el tiempo». La idea de subastar el tiempo partió de Oliva Arauna, y fue El Instante el que construyó un guion convocando a los actores y diseñando un escenario.

«Casas para Animales» ${ }^{18}$, exposición celebrada entre noviembre y diciembre 2018, fue un homenaje al historiador del arte Ángel González García en relación con su libro La arquitectura nunca duerme (González, 2014). En esta

18 Concebido por Arquitectura Enguita \& Lasso de la Vega, José María Sicilia, Miguel Albero y El Instante. publicación su autor analiza los sorprendentes proyectos no construidos de Enguita \& Lasso de la Vega, que de alguna manera se emparentan con la forma de construcción de nidos o hábitat de los animales. La muestra en la sede de El Instante parte de la idea «si la humanidad desapareciera, los animales habitarían sus espacios» como en el principio de los tiempos. El mundo animal se haría dueño de aquellos espacios construidos y ocupados por el hombre, civilización y naturaleza, «un artificio común a hombres y animales -el de construir casas- que deriva en un enigmático e incierto intercambio de papeles». Es todo un proceso que induce a la meditación, a una visión metafísica sobre el tiempo y la ausencia del individuo en el mundo.

De otra manera, en la muestra «Pliegue, Origami curvado-plegado de Jun Mitani. Servicios de mesa» (septiembre a octubre 2019) se propuso una doble mirada sobre el pliegue. El papel se dobla, se abre, y al someterse a fórmulas de computación, más el alimento fermentado, se crean nuevas e insospechadas imágenes. «El pliegue contiene en sí mismo los planos de la existencia: la materia y el espíritu. Verso/reverso. El pliegue es una fuente inagotable de imágenes y pensamientos ${ }^{19}{ }$.

Pero, asimismo, el mundo del libro tiene un lugar esencial en la programación de El Instante. Por un lado las presentaciones de libros ${ }^{20}$, entre las que cabe destacar aquella dedicada a Quico Rivas, escritor y polifacético cultural que jugó un papel decisivo en las décadas 1970 y 1980. Sus amigos artistas e intelectuales de su generación le homenajearon con la obra El Poeta Sordo (55 jaiqús), Huerga y Fierro editores, que se presentó en diciembre del 2019. Por otro, El Instante Ediciones ofrece también sus propios proyectos, entre ellos el fotolibro Las Patrañas de Miguel

19 En colaboración con Jun Mitani y Miguel de Torres. Más información en: https://www.elinstantefundacion.org/elpliegue 20 Otra presentación del libro fue el titulado ¿qué nube?, fotografías de Mauricio D’Ors y textos de Eugenio D’Ors, que tuvo lugar en abril del 2019 con las intervenciones de Lola Garrido y José Luis Gallero. 


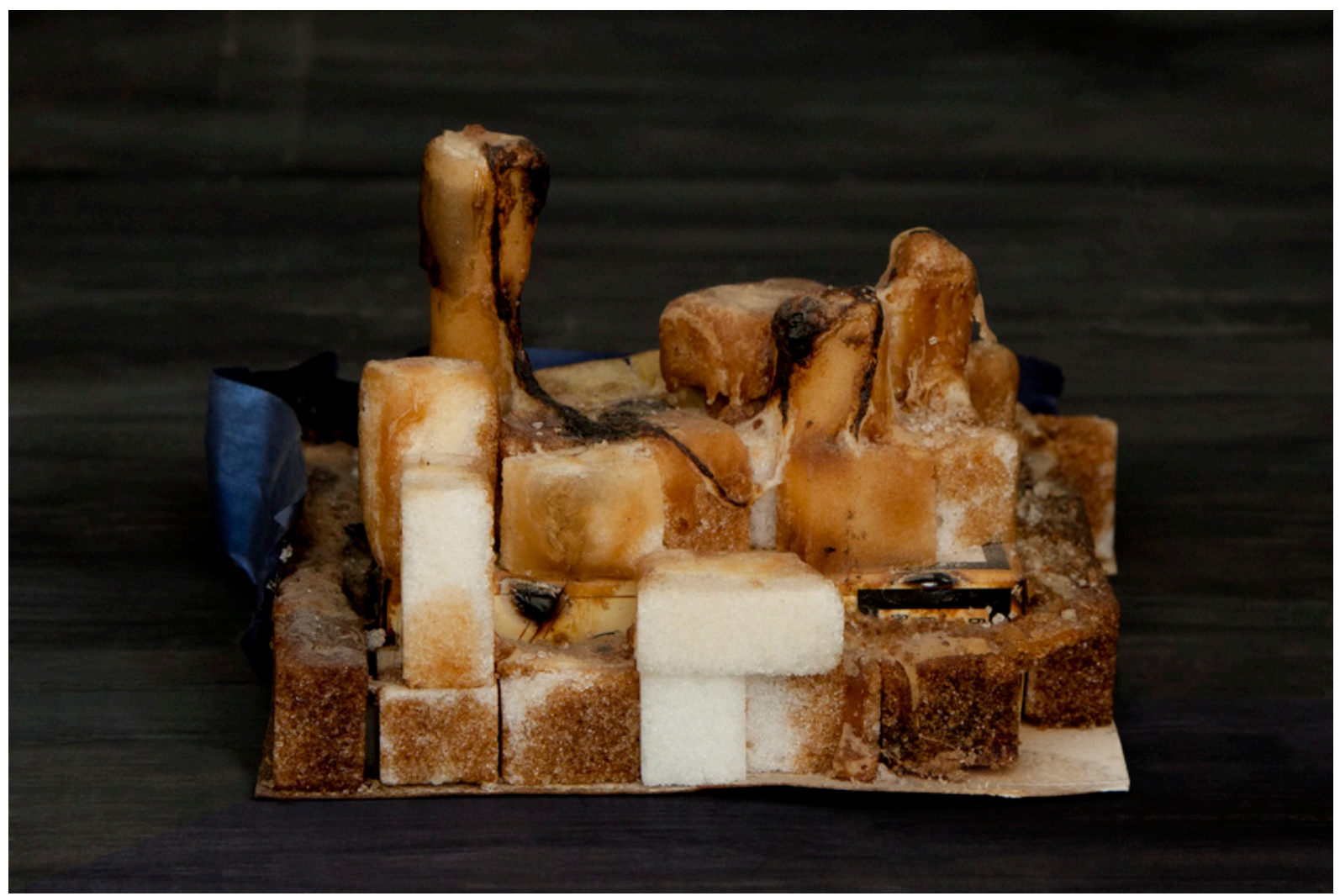

Javier Campano. Las Patrañas de Miguel Ángel Campano (2019). Fotografía: El Instante Fundación.

Ángel Campano de Javier Campano u otras ediciones en colaboración con diferentes artistas.

Una muestra de trabajos de Ediciones El Instante (Madrid) se presentó en ARCO2O, en la sección ArtsLibris. Esta Feria Internacional del Libro de Artista y Edición Contemporánea, surgida en Barcelona y que este es el quinto año que se presenta en ARCO, tiene como meta difundir la edición contemporánea de libros de artista a la vez que impulsa y fomenta que los expositores entren en el circuito internacional. Al mismo tiempo, en este espacio de encuentro se da a conocer el rumbo que va tomando la edición en arte en el futuro. Precisamente por ello, la participación de El Instante en esta Feria del Libro le permite poner el foco sobre sus ediciones más allá de su sede. Esta feria es, en palabras de Rocío Santa Cruz, directora de ArtsLibris, y recogidas por s. H. (2020: 9): «Un fenómeno que reclama atención porque no deja de crecer y que ya va mucho más allá del artista que hace su fotolibro».

Paralizada la actividad debido a los sucesivos estados de confinamiento durante la pandemia del coronavirus, desde marzo 2020, El Instante Fundación buscó una alternativa, para no frenar su actividad ni perder el contacto con el público, proyectando una acción participativa titulada Sueños en tiempos del coronavirus. Consistía en una invitación general a enviar al correo electrónico de El Instante un sueño (una imagen y una breve narración) para luego ser subidos a la red ${ }^{21}$. La obra final fue el resultado de las aportaciones de todos los participantes, una obra común. Siguiendo

21 Los sueños recogidos se fueron colgando en Facebook y en la web de El Instante Fundación hasta el verano de 2020. Puede consultarse el resultado final del proyecto Sueños en tiempos del coronavirus en: https://www.elinstantefundacion.org/suenosentiemposdelcoronavirus 
a Hegel, resultan muy apropiadas las palabras que introducen este proyecto: «Para saber lo que nos está pasando tenemos que conocer lo que nos cuentan los sueños. Si reuniéramos los sueños de un momento histórico determinado, veríamos surgir una exactísima imagen del espíritu de ese periodo». Una oportunidad ganada al tiempo, que ha sido aprovechada por El Instante al idear y poner en práctica su propósito primero: detener el instante con este llamamiento público y empático.

$Y$ para que aquellos instantes, eventos, gestos, momentos no se escapen, con la consigna «Instantegram es más que Instagram» se incluye un diario de las acciones artísticas de El Instante; momentos únicos que se perpetúan con la imagen captada de la cámara.

\section{Conclusión}

Vivir en el presente, una frase, casi una consigna que cada uno tenemos interiorizada pero que difícilmente logramos satisfacer del todo; pues no se trata de aprovechar con urgencia ese tiempo que nos obliga a no parar y al que inapelablemente nos vemos arrastrados.

Es un instante de oro el que propone $\mathrm{El}$ Instante Fundación, al que intenta llevarnos con sus propuestas culturales que exigen, al contrario de lo que parecería, una atención extrema; una concentración en esa pequeña cosa que si no la captamos ahora luego ha desaparecido. La idea de El Instante se incorpora al mundo artístico como algo distinto, a la vez entrañable y sencillo, a la oferta más espectacular de sus vecinos.

Creo que nos encontramos en un momento histórico de dejar a cierto lado, sin alejarse, el ruido mediático, incluida la peor praxis de la crítica de arte: «Uno de los males de la crítica de arte actual es precisamente que dirige en exceso la conciencia y la voluntad del individuo canalizándolo hacia supuestos aceptados por la mayoría de la sociedad» (Francés, 1994: 15). Las apuestas de El Instante conducen hacia el pensamiento reflexivo, hacia la vivencia de experiencias personales y emotivas en el encuentro con las obras exhibidas en sus espacios, evitando así el excesivo dirigismo ruidoso de los medios de comunicación.

\section{REFERENCIAS Y BIBLIOGRAFÍA}

ÁLAMO NúÑEZ, Enrique del (2020) «Los espacios formales y reglados», en Manual Atalaya. Apoyo a la gestión Cultural. Disponible en http://atalayagestioncultural.es/capitulo/espacios-formales-reglados [Fecha de consulta 1/09/2020]

Angosto, Diana (2019) «La sombra del oro», en El Instante Fundación. Junio. Disponible en https://www. elinstantefundacion.org/goldfilm [Fecha de consulta $15 / 09 / 2020$ ]

CAlvo SERraller, Francisco (1984) «La remodelación de la estación de Atocha, una clave urbanística para el futuro Madrid», El País, 8 abril, 28.

COAM (2014) "Centro Cívico Integrado "Arganzuela" Inmueble F2.562RO», en Fundación COAM. Febrero. Disponible en http://guia-arquitectura-madrid.coam.org/\#inm.F2.562 [Fecha de consulta 5/09/2020]

FRANCÉs, Fernando (1994) «Apuntes a la crítica de arte», en Rekarte, periódico sala Rekalde, mayo, 8.

Fuente, Ulises (2017) «Esther Suárez: "Hay que encontrar respuestas, y el arte las tiene"”, en $L a$ Razón, Madrid, 16 Marzo. Disponible en https:// www.larazon.es/cultura/esther-suarez-hayque-encontrar-respuestas-y-el-arte-las-tieneEA14726839/ [Fecha de consulta 5/09/2020]

GONZÁLEZ GARCíA, Ángel (2014) La arquitectura nunca duerme. Enguida \& Lasso de la Vega. Obras y proyectos, Madrid: This Side up.

H., S. (2020) «ArtsLibris, coleccionar ediciones», en Cultura/s La Vanguardia, 22 febrero, 6.

LAyUno rosas, Ma Ángeles (2004) Museos de arte contemporáneo en España: del «palacio de las artes» a la arquitectura como arte, Gijón: Trea.

López DE LUCIO, Ramón (2003) Arquitectura de Madrid. Introducción, Madrid: Fundación COAM. 


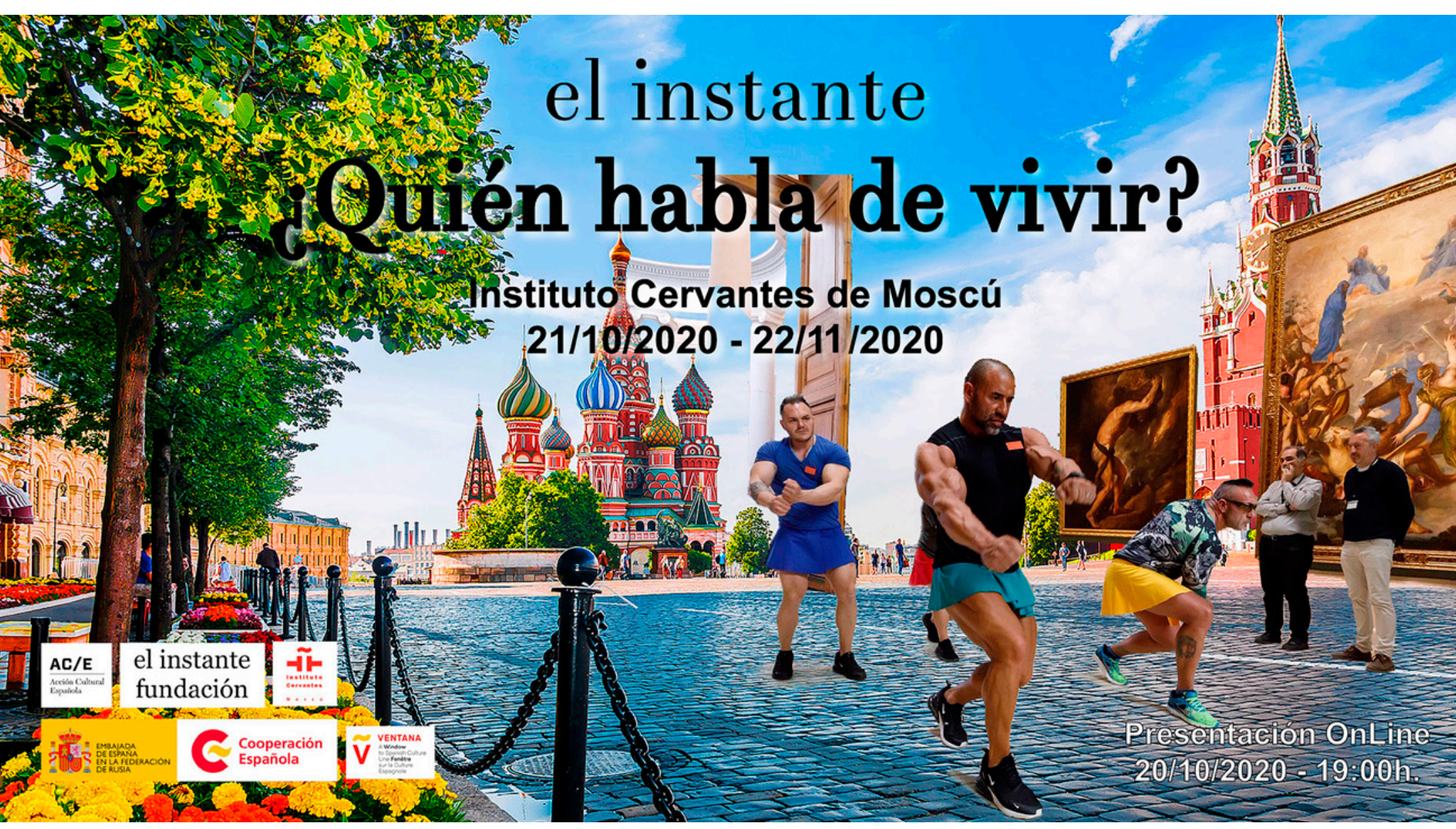

Cartel de la presentación en el Instituto Cervantes de Moscú de la película ¿Quién habla de vivir? (Sobre vivir en el Prado), 2020, dirigida y producida por El Instante. Fotografía: El Instante Fundación.

MATthews, Wade (2012) Improvisando: La libre creación musical, Madrid: Turner.

MEDialdEA, Sara (2001) «La antigua Estación de autobuses se hace centro público», en $A B C$, Madrid, 3 de julio. Disponible en https://www.abc.es/espana/ madrid/abci-antigua-estacion-autobuses-hace-centro-publico-200107030300-32569_noticia.html [Fecha de consulta 10/09/2020]

ORDINE, Nuccio (2013) La utilidad de lo inútil. Manifiesto, Barcelona: Acantilado.

RIVERO MORENO, Luis D. (2010) «Entre la eternidad y la caducidad. El Arte Contemporáneo en el abismo del tiempo», HUM36, Papeles de Cultura Contemporánea, diciembre, 12: 43.

RUBio sotés, Francisca (1982) «El barrio de Palos de Moguer dentro del Ensanche sur de Madrid», en Anales De Geografía De La Universidad Complutense,
2: 217. Disponible en https://revistas.ucm.es/index. php/AGUC/article/view/AGUC8282110217A

[Fecha de consulta 15/09/2020]

Recibido el 6 del 10 de 2020

Aceptado el 3 del 11 de 2020

BIBLID [2530-1330 (2020): 128-145]

Este artículo forma parte del proyecto de investigación Arte, Arquitectura y Patrimonio en los procesos de construcción de la imagen de los nuevos enclaves culturales (del Distrito al Territorio). Ref. PGC2018094351-B-C43. Ministerio de Ciencia, Innovación y Universidades. 2019-2022. 